Article

\title{
White Light-Emitting Devices Based on Inorganic Perovskite and Organic Materials
}

\author{
Shuming Chen ${ }^{1}$, Chen Chen ${ }^{2}$, Cong Bao ${ }^{2}$, Muhammad Mujahid ${ }^{2}, \mathrm{Ye} \mathrm{Li}^{1, *}$, Ping Chen ${ }^{2}$ \\ and Yu Duan $1,2, *$ \\ 1 College of Science, Changchun University of Science and Technology, Changchun 130012, China; \\ shuming828@163.com \\ 2 State Key Laboratory on Integrated Optoelectronics, College of Electronic Science and Engineering, \\ Jilin University, Changchun 130012, China; cchen18@mails.jlu.edu.cn (C.C.); \\ baocong16@mails.jlu.edu.cn (C.B.); mujahidiqbal133@gmail.com (M.M.); pingchen@jlu.edu.cn (P.C.) \\ * Correspondence: liye@cust.edu.cn (Y.L.); duanyu@jlu.edu.cn (Y.D.); \\ Tel.: +86-0431-8558-2346 (Y.L.); +86-0431-8516-8242-8217 (Y.D.)
}

Received: 18 January 2019; Accepted: 19 February 2019; Published: 22 February 2019

\begin{abstract}
Perovskite-based materials have attracted considerable attention in photoelectric devices. In this paper, we report the one-step fabrication of spin-coated $\mathrm{CsPbBr}_{2.5} \mathrm{I}_{0.5}$ perovskite films doped with PAN (polyacrylonitrile) polymer. A red perovskite LED (PeLED) composite film was fabricated which featured a maximum luminance value of $657 \mathrm{~cd} / \mathrm{m}^{2}$ at $8 \mathrm{~V}$. We fabricated white PeLEDs by combining hole transporting layer material emission, perovskite-polymer composite material PAN:CsPbBr $2.5 \mathrm{I}_{0.5}$, and pure inorganic perovskite $\mathrm{CsPbBr}_{3}$ as a luminescent layer. The maximum luminance of the device was $360 \mathrm{~cd} / \mathrm{m}^{2}$ at $7 \mathrm{~V}$, and the color coordinate was $(0.31,0.36)$. We obtained an ideal white light-emitting device that paves the way for further development of white PeLEDs.
\end{abstract}

Keywords: inorganic perovskite; polymer; white PeLED

\section{Introduction}

Electroluminescent devices have been the focus of many studies in the fields of physics and chemistry. In comparison to traditional inorganic semiconductors and organic small molecules [1-3], materials based on $\mathrm{ABX}_{3}$ perovskites have attracted the attention of many researchers due to their excellent photoelectric properties. State-of-the-art perovskite solar cells already feature an efficiency of $22.1 \%$, which is comparable to photovoltaic cells made from traditional inorganic semiconductor materials [4-6]. Perovskite-based materials are also used as effective low-threshold gain media in optical pump lasers $[7,8]$. Moreover, perovskite light-emitting devices also present other advantages such as high photoluminescence quantum yield (PLQY), easy adjustment of color luminescence, and high color purity [9-12]. The excellent electronic and optical properties of these materials are ideal for high-performance optoelectronic devices and light-emitting diodes (LEDs) for displays and illumination. White light plays an important role in the fields of illumination and display, as the main light source of solid-state devices and backlights in liquid-crystal displays [13]. Therefore, research into white light-emitting perovskite devices is of great significance. Since the first room-temperature electroluminescent device manufactured in 2014, great progress has been made in the application of perovskite materials as light-emitting devices, especially for green light-emitting devices based on lead perovskite bromide (e.g., $\mathrm{MAPbBr}_{3}$ and $\mathrm{CsPbBr}_{3}$ ). After a relatively short development period, the luminance and external quantum efficiency (EQE) of green perovskite LEDs reached 10,000 cd/ $\mathrm{m}^{2}$ and $10 \%$, respectively [14]. The Snaith group first reported green and infrared perovskite light-emitting diodes (PeLEDs) with tunable band gaps via changes in the chemical composition. These PeLEDs achieved luminescence of $364 \mathrm{~cd} / \mathrm{m}^{2}$ and radiation of $6.8 \mathrm{Wsr}^{-1} \mathrm{~m}^{-2}$ [15]. 
Organic-inorganic hybrid perovskite materials based on methylamine $\left(\mathrm{CH}_{3} \mathrm{NH}_{3}\right)$ are very sensitive to moisture and heat, leading to poor stability of PeLEDs [16,17]. An effective strategy for improved heat and humidity stability of perovskite solar cells involves replacing the MA cations in the perovskite with formazan (FA) or Cs [18-20]. Therefore, partial or complete cation substitution can produce more stable PeLEDs. Although FA cations are more stable than MA cations, the former is still susceptible to humidity [21]. Therefore, the most stable PeLED can be obtained by substituting inorganic Cs cations for unstable organic cations [22].

In order to achieve high-efficiency PeLEDs based on perovskite thin films, dense and uniform grain and reducing defects are prerequisites for high-quality perovskite thin films, which is beneficial to enhance radiation recombination and inhibition of nonradiative recombination $[23,24]$. Evidently, the morphology of the perovskite layer is very important to the performance of PeLEDs. A successful protocol to achieve this involves mixing perovskite precursors with polymeric materials, such as polyethylene oxide (PEO) [25] and polyacrylonitrile (PAN) [26].

In this work, we doped polymer material PAN into inorganic perovskite $\mathrm{CsPbBr}_{2.5} \mathrm{I}_{0.5}$ precursor solution. High coverage and average PAN:CsPbBr $2.5 \mathrm{I}_{0.5}$ mixed film was obtained by the one-step spin-coating method, and we fabricated a red perovskite device with the mixed film as the luminescent layer, and the maximum luminescence of the device was $657 \mathrm{~cd} / \mathrm{m}^{2}$ at $8 \mathrm{~V}$. At the same time, we fabricated a multi-luminescent layer structure white PeLED by combining organic small molecule material NPB, perovskite-polymer composite material $\mathrm{PAN}: \mathrm{CsPbBr}_{2.5} \mathrm{I}_{0.5}$, and pure inorganic perovskite $\mathrm{CsPbBr}_{3}$ as a luminescent layer. The maximum luminescence of the device was $360 \mathrm{~cd} / \mathrm{m}^{2}$ at $7 \mathrm{~V}$, the current efficiency was $0.2 \mathrm{~cd} / \mathrm{A}$, and the color coordinate of the PeLED was $(0.31,0.36)$. Although the brightness and efficiency were lower, the exciton distribution of the white PeLED under the multi-luminescent layer structure was consistent with ideal white emission.

\section{Results and Discussion}

\subsection{Device Structure}

Figure 1a shows a scheme of the red PeLED devices which used ITO as the anode, PEDOT: PSS as the hole transport layer (HTL), PAN:CsPbBr $2.5 \mathrm{I}_{0.5}$ as the red luminescent layer, TPBi as the electron transport layer (ETL), Liq as the electron injection layer (EIL), and $\mathrm{Al}$ as the cathode. Figure $1 \mathrm{~b}$ shows the structure of the white PeLED device which employed PAN:CsPbBr $2.5 \mathrm{I}_{0.5}, \mathrm{NPB}$, and $\mathrm{CsPbBr}_{3}$ as the red, blue, and green light-emitting layers respectively. The hole transport layer, electron transport layer, and electron injection layer of the white PeLED were the same as those in the red PeLED. Figure 1c shows the chemical structure of PAN.

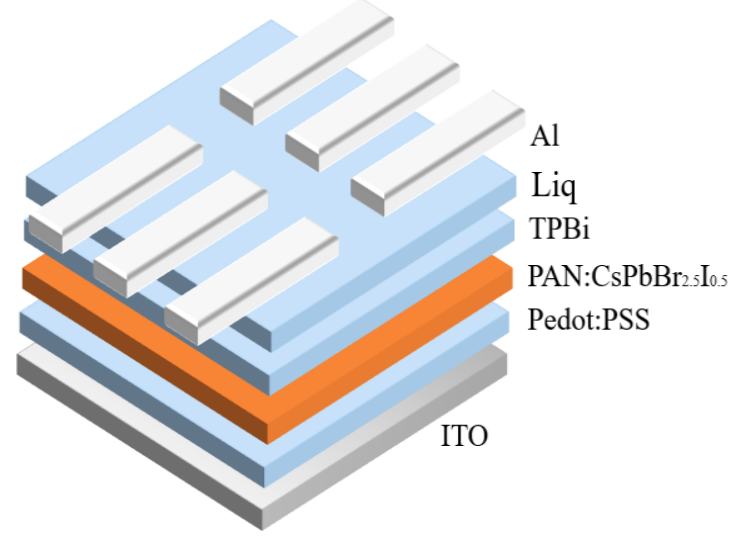

(a)

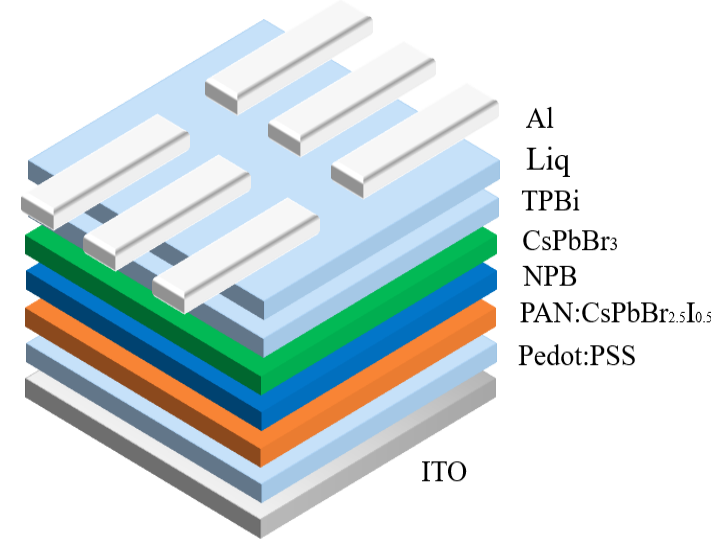

(b)

Figure 1. Cont. 


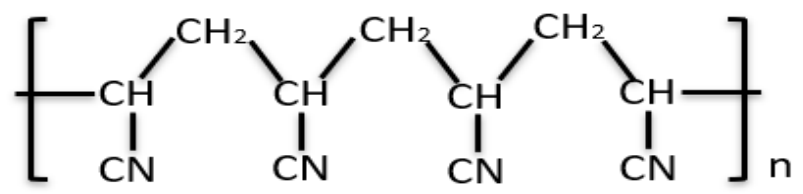

(c)

Figure 1. (a) The device structure diagram of a red perovskite light-emitting diode (PeLED); (b) the device structure diagram of a white PeLED; (c) the chemical structure of polyacrylonitrile (PAN).

\subsection{Characterization of Perouskite Films}

The effect of PAN on the surface morphology of the light-emitting layer was investigated using scanning electron microscopy (SEM). Figure 2 shows a surface image of a perovskite film with and without PAN. The bare perovskite film featured numerous pinholes and poor coverage, which causes unnecessary nonradiative recombination [27]. The PAN:CsPbBr $2.5 \mathrm{I}_{0.5}$ mixed film exhibited a continuous crystal form, a drastic reduction in the number of pinholes, and almost no voids. The coverage and uniformity were remarkably improved. Introduction of PAN caused the concomitant increase of the perovskite crystals size. Consistent with the SEM observations, atomic force microscope (AFM) images of the bare perovskite film exhibited a roughness of $6 \mathrm{~nm}$ (Figure 3). This high surface roughness results in an inferior interface with the NPB layer, which severely limits the performance of the PeLEDs [28]. The film coated with PAN was characterized by a roughness of $4.7 \mathrm{~nm}$, which represents a considerable improvement in terms of the film surface smoothness. These results suggest that the introduction of the PAN plays an essential role in controlling the morphology of the perovskite, which means that the mixed film can be used to fabricate more efficient light-emitting devices. We used the stylus profiler to measure the thickness of $\mathrm{CsPbBr}_{2.5} \mathrm{I}_{0.5}$ and $\mathrm{PAN}: \mathrm{CsPbBr}_{2.5} \mathrm{I}_{0.5}$ films at $2000 \mathrm{rpm} / \mathrm{s}$ and $4000 \mathrm{rpm} / \mathrm{s}$ respectively. The thickness at $2000 \mathrm{rpm} / \mathrm{s}$ was $40 \mathrm{~nm}$ and $45 \mathrm{~nm}$, and the thickness at $4000 \mathrm{rpm} / \mathrm{s}$ was $17 \mathrm{~nm}$ and $20 \mathrm{~nm}$. The film thickness of the mixed solution containing the polymer is slightly higher than that of the pure perovskite solution at the same rotation speed because the viscosity of the solution is increased by the introduction of the polymer. It can be seen that the film thickness is mainly determined by the spin coating speed, and the effect of the PAN addition on the film thickness is slight.

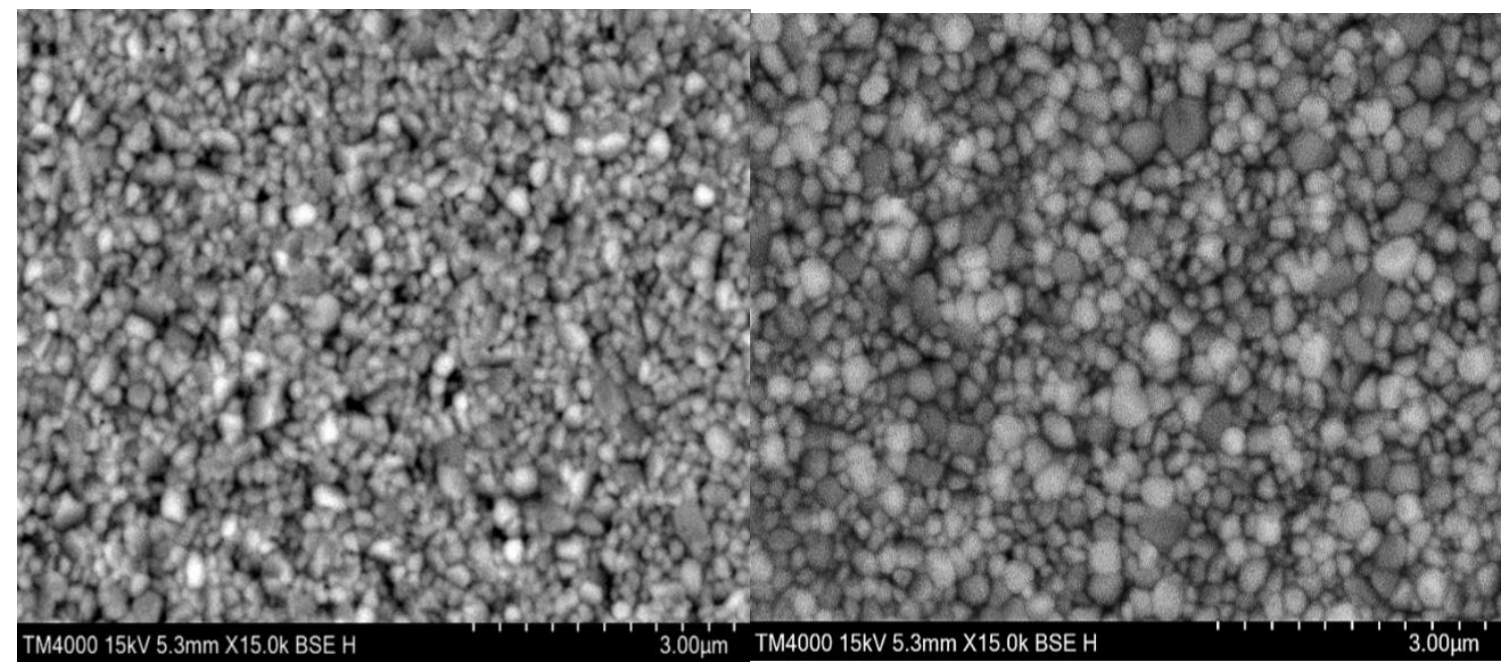

(a)

(b)

Figure 2. (a) SEM image of $\mathrm{CsPbBr}_{2.5} \mathrm{I}_{0.5}$ film without PAN; (b) SEM image of $\mathrm{CsPbBr}_{2.5} \mathrm{I}_{0.5}$ film with PAN. 


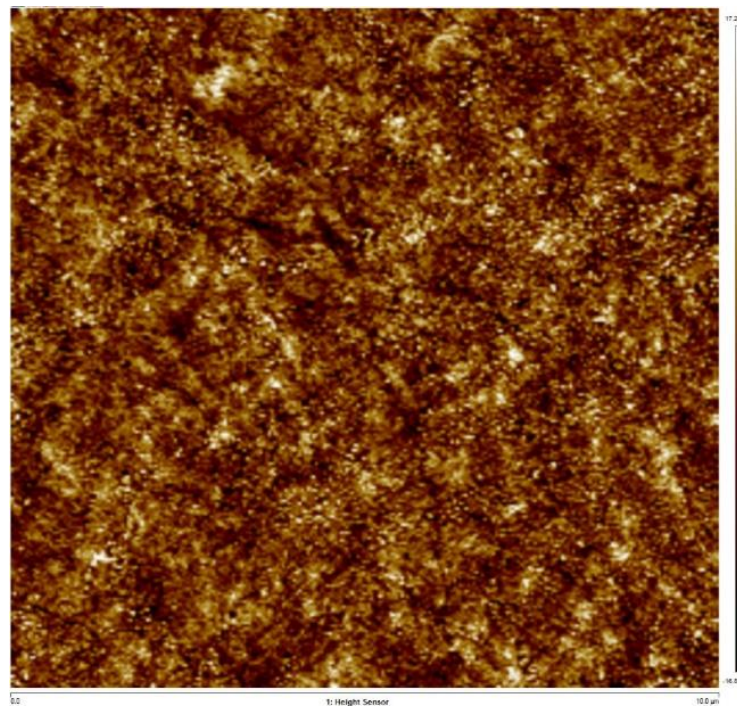

(a)

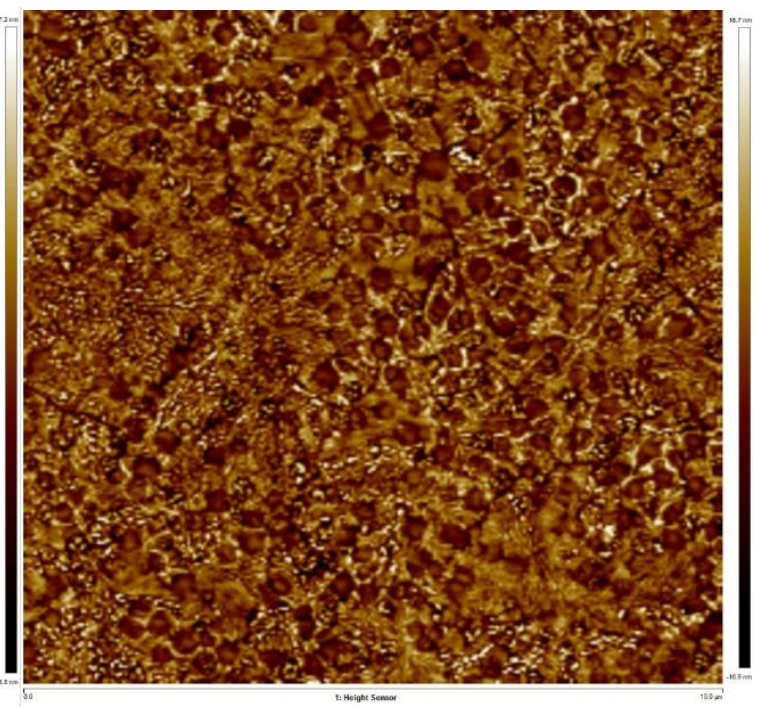

(b)

Figure 3. (a) Atomic force microscope (AFM) image of $\mathrm{CsPbBr}_{2.5} \mathrm{I}_{0.5}$ film without PAN; (b) AFM image of $\mathrm{CsPBr}_{2.5} \mathrm{I}_{0.5}$ film with PAN.

Figure 4 shows the photoluminescence (PL) spectra used to evaluate the optical properties of the $\mathrm{CsPbBr}_{2.5} \mathrm{I}_{0.5}$ films. The excitation wavelength was $420 \mathrm{~nm}$, and the PL spectrum peak was located at $720 \mathrm{~nm}$ with a full width at half maximum (FWHM) of about $20 \mathrm{~nm}$. The increase in PL strength is due to surface passivation of the polymer [29]. There are a large number of defects in the perovskite film, resulting in exciton quenching and large leakage current. As shown in the SEM image, due to the addition of PAN, the pores on the surface of the film are significantly reduced to form a more uniform film. Notably, the PL intensity of the composite film is significantly higher than that of the pure perovskite film, which indicates that adding PAN can effectively improve the luminescence properties of perovskite film.

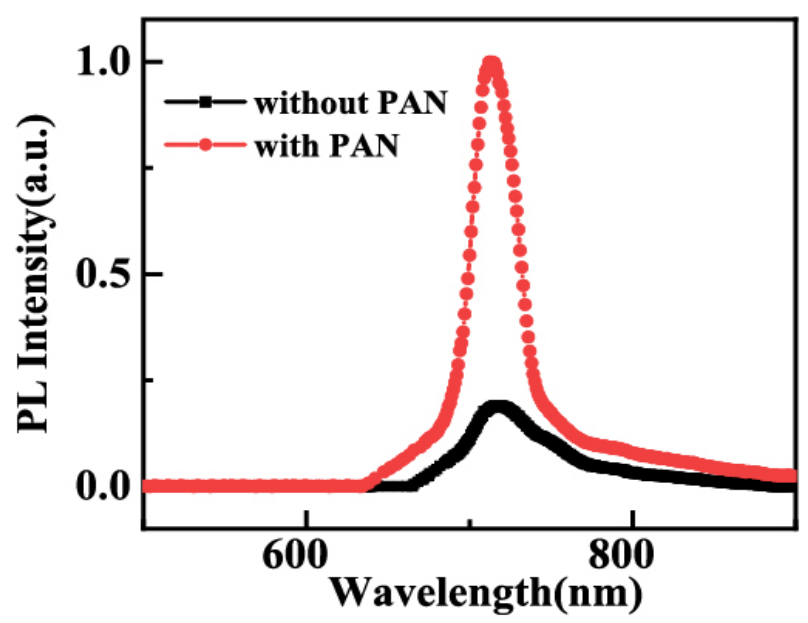

Figure 4. Photoluminescence spectra of the $\mathrm{CsPbBr}_{2.5} \mathrm{I}_{0.5}$ film.

\subsection{Performance of Red PeLEDs}

In order to study the performance of PeLED devices composed of PAN:CsPbBr $2.5 \mathrm{I}_{0.5}$ mixed films as light-emitting layers, we fabricated four groups of red PeLEDs at the following speeds: $2000 \mathrm{rpm} / \mathrm{s}$ without PAN, $2000 \mathrm{rpm} / \mathrm{s}$ with PAN, $4000 \mathrm{rpm} / \mathrm{s}$ without PAN, and $4000 \mathrm{rpm} / \mathrm{s}$ with PAN. The red PeLED current density-voltage $(\mathrm{J}-\mathrm{V})$ curve shown in Figure 5a exhibited typical diode characteristics 
of conventional PeLEDs; mainly, the current density increased exponentially with voltage. It is worth noting that the current density of the device decreased greatly due to the low conductivity of the PAN polymer [30]. Furthermore, the current density of the device at high speeds was slightly lower than that at lower speeds. Figure $5 b$ shows the luminance-voltage (L-V) curves. The device with PAN fabricated at $2000 \mathrm{rpm} / \mathrm{s}$ exhibited a maximum luminance value of $657 \mathrm{~cd} / \mathrm{m}^{2}$ at $8 \mathrm{~V}$, whereas the device without PAN fabricated at $2000 \mathrm{rpm} / \mathrm{s}$ showed a maximum luminance value of $582 \mathrm{~cd} / \mathrm{m}^{2}$ at $8 \mathrm{~V}$. The brightness of the device increased by about $13 \%$ - such an effect proves that the PAN:CsPbBr ${ }_{2.5} \mathrm{I}_{0.5}$ composite film improves the performance of the device. In addition, the luminance of the device fabricated at $2000 \mathrm{rpm} / \mathrm{s}$ was higher than that fabricated at $4000 \mathrm{rpm} / \mathrm{s}$. Adding PAN at $4000 \mathrm{rpm} / \mathrm{s}$ only showed very weak luminescence. This observation is explained as a consequence of the higher viscosity of the perovskite solution containing PAN, and the inferior morphology of the composite film at very high speeds. Since the thickness of the perovskite layer decreased at higher rotating speeds, a very thin perovskite film will also affect the performance of the device. We also spin-coated the PAN:CsPbBr $2.5 \mathrm{I}_{0.5}$ solution at a low speed (1000 rpm/s). Since the viscosity of the solution was increased after the polymer was added to the perovskite precursor solution, the solution layer was thick, and there were more residual solvents. This resulted in a less uniform nucleation point, leaving a distinct pattern on the substrate after spin coating. The brightness of the device obtained on this basis is very uneven, and the performance is poor. Figure 6 shows the representative EL spectrum of a PeLED featuring a maximum intensity peak at $680 \mathrm{~nm}$.

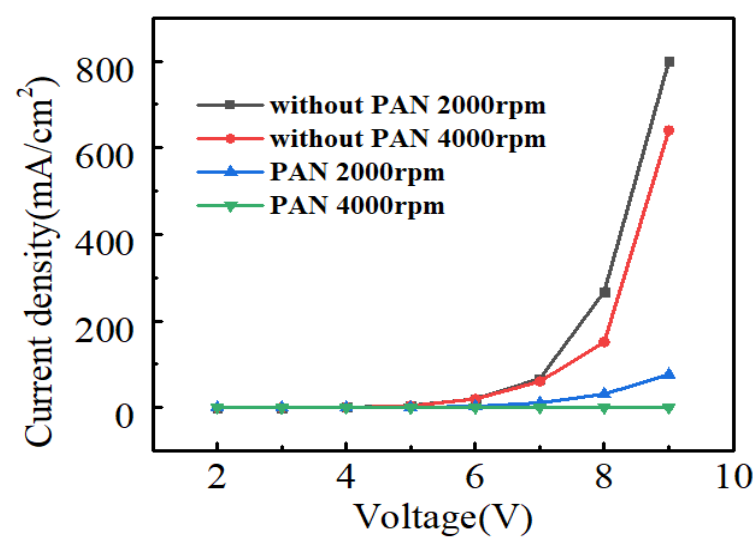

(a)

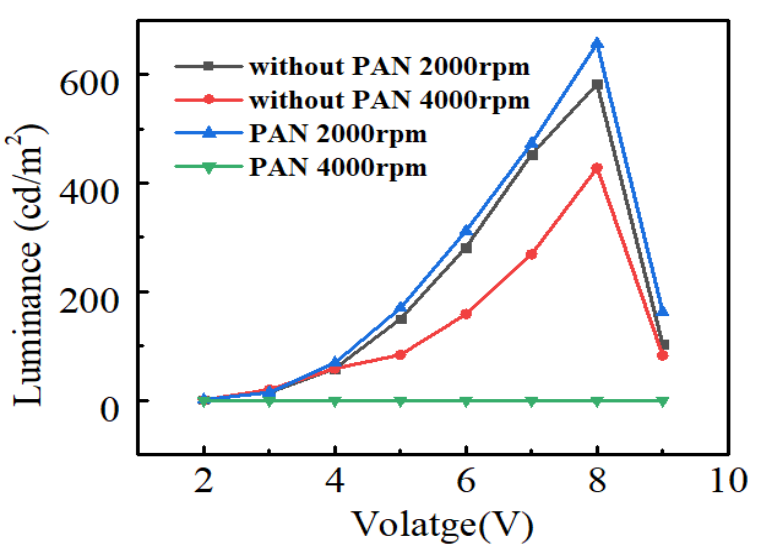

(b)

Figure 5. Current-luminance-voltage (I-L-V) characteristic curve of a red PeLED: (a) Current density-voltage $(\mathrm{J}-\mathrm{V})$ curve; (b) luminance-voltage $(\mathrm{L}-\mathrm{V})$ curve.

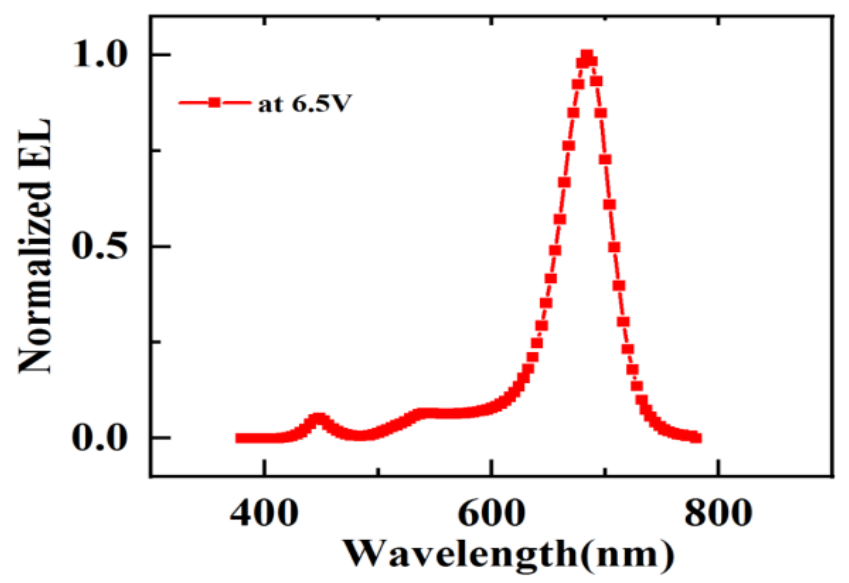

Figure 6. Electroluminescence spectra of a red PeLED. 


\subsection{Performance of White PeLEDs}

The current-voltage-luminance (J-V-L) curves for the white PeLED are shown in Figure 7. We tested the performance of the devices with different NPB thicknesses. The current density-voltage (J-V) curve is shown in Figure 7a. The growth of a $5 \mathrm{~nm}$ thick NPB PeLED exhibited a higher current density at low voltages compared to $10 \mathrm{~nm}$ thick NPB PeLED films. As the voltage increased, the difference in current density decreased. Luminance-voltage $(\mathrm{L}-\mathrm{V})$ curves and current efficiency-voltage $(\mathrm{CE}-\mathrm{V})$ curves are shown in Figure $7 \mathrm{~b}, \mathrm{c}$, respectively. Applying a voltage exceeding the turn-on voltage $(4 \mathrm{~V})$ of the device resulted in an exponential increase in luminance due to the concomitant increase in current density. The 10nm thick NPB PeLED reached a maximum luminance value of $360 \mathrm{~cd} / \mathrm{m}^{2}$ at $7.5 \mathrm{~V}$ and a maximum current efficiency value of $0.2 \mathrm{~cd} / \mathrm{A}$. Above this voltage, the Joule heat generated at large currents caused deterioration of the device and a gradual decrease in luminance. Compared with the $10 \mathrm{~nm}$ thick NPB PeLED, the $5 \mathrm{~nm}$ thick NPB white PeLED had a maximum brightness value of $241 \mathrm{~cd} / \mathrm{m}^{2}$ and a current efficiency of $0.1 \mathrm{~cd} / \mathrm{A}$, indicating that the thicker NPB made a certain improvement on device performance. The effect of NPB layer thickness on efficiency was due to the hole transport feature of NPB which has a blocking effect on electron transport, and the increase of NPB thickness contributed to carrier balance. However, as the NPB thickness increased, the device exhibited blue emission, as too many electron holes recombined in the NPB layer. Figure 7d shows the EL spectrum of white light-emitting PeLEDs. Under the condition of electroluminescence, the white light emitted by the device was a mixed blue, green, and red emission. The luminescence peak at $472 \mathrm{~nm}$ arose from the intrinsic blue light emission of the organic NPB layer, whereas the luminescence peaks at $532 \mathrm{~nm}$ (green light) and $608 \mathrm{~nm}$ (red light) originated from the intrinsic emission of the inorganic $\mathrm{CsPbBr}_{3}$ and $\mathrm{CsPbBr}_{2.5} \mathrm{I}_{0.5}$ materials, respectively. In addition, the devices with a $10 \mathrm{~nm}$ thick NPB layer exhibited stronger blue emission than those with a $5 \mathrm{~nm}$ thick layer. The CIE coordinate of the white PELED growing $10 \mathrm{~nm}$ NPB was $(0.31,0.36)$, which is consistent with pure white emission.

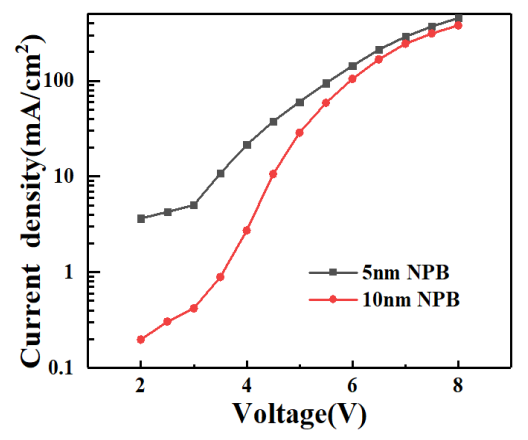

(a)

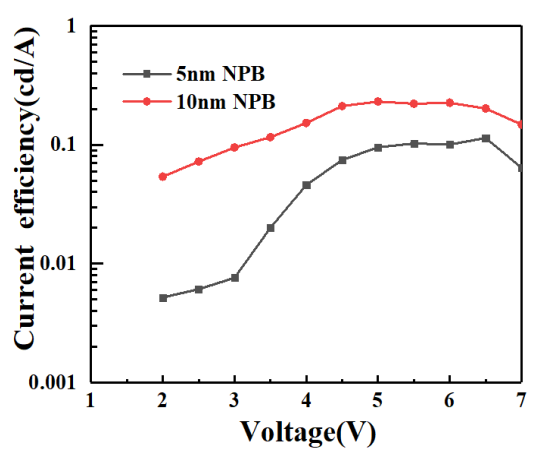

(c)

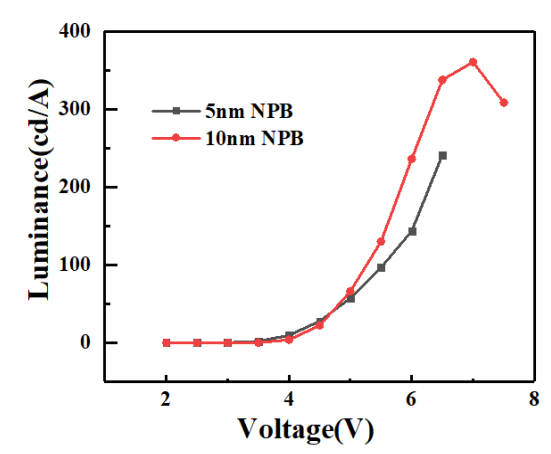

(b)

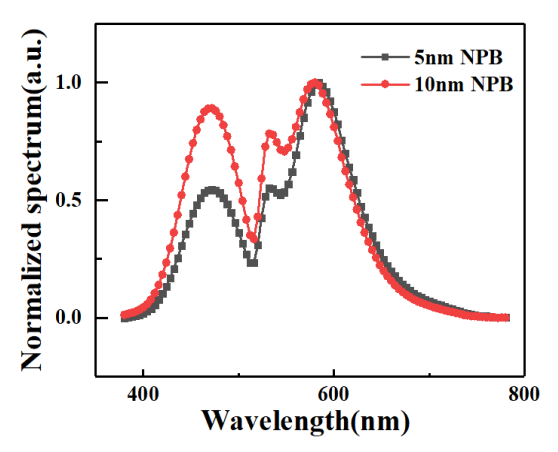

(d)

Figure 7. Current-luminance-voltage (I-L-V) characteristic curve and electroluminescence spectra of the white PeLED: (a) Current density-voltage (J-V) curve; (b) luminance-voltage (L-V) curve; (c) current efficiency-voltage $(\mathrm{CE}-\mathrm{V})$ curve; (d) electroluminescence spectra of the white PeLED device. 
Figure 8a shows the working mechanism of the white PeLED based on the energy band diagram. Driven by the forward voltage, holes from the highest occupied molecular orbital (HOMO) of PEDOT:PSS and electrons from the lowest unoccupied molecular orbital (LUMO) of TPBi hopped to the interface of the luminescent layer to form excitons upon entering the luminescent layer. Overall, the 10nm thick NPB white light-emitting device exhibited significantly higher luminance and stronger blue emission than that of a device $5 \mathrm{~nm}$ in thickness (Figure 7). We speculate this is because as the thickness of NPB increases, the recombination region of electrons and holes also increases. In the case of $5 \mathrm{~nm} \mathrm{NPB}$, the number of excitons does not reach saturation, and as the thickness of NPB increases, there are more carrier recombinations in the luminescent layer which produces more excitons, resulting in higher luminance. A schematic diagram of the exciton distribution is shown in Figure $8 b$.

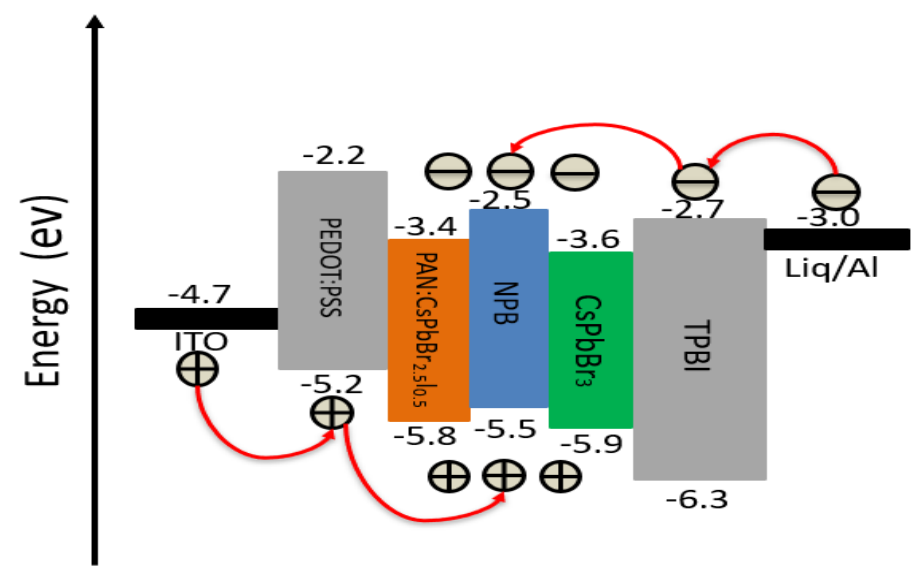

(a)
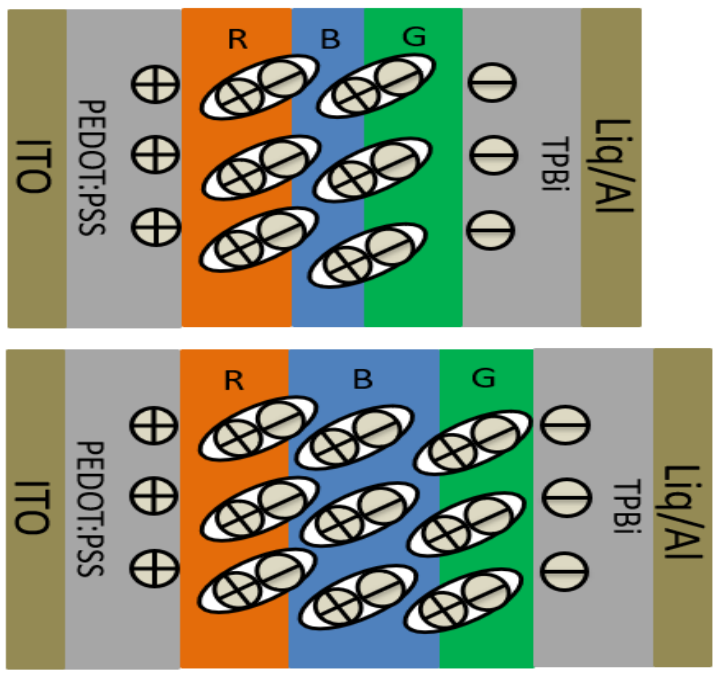

(b)

Figure 8. (a) Device energy level diagram of the white PeLED; (b) schematic diagram of the exciton distribution in the luminescent layer.

\section{Materials and Methods}

Cesium bromide (CsBr), lead bromide $\left(\mathrm{PbBr}_{2}\right)$, iodine bromide $\left(\mathrm{PbI}_{2}\right)$, 1,3,5-Tris(1-phenyl-1H-benzimidazol-2-yl)benzene (TPBi), 8-Hydroxyquinolinolato-lithium (Liq), 
and $\mathrm{N}, \mathrm{N}^{\prime}$-Bis(naphthalen-1-yl)-N, $\mathrm{N}^{\prime}$-bis(phenyl)-benzidine (NPB) were purchased from $\mathrm{Xi}^{\prime}$ an Polymer Light Technology Cory (Xi'an, China). Polyacrylonitrile (PAN, average $\mathrm{M}_{\mathrm{w}} 150,000$ ) were purchased from Sigma-Aldrich (Shanghai, China).

$\mathrm{CsBr}, \mathrm{PbBr}_{2}$, and $\mathrm{PbI}_{2}$ were dissolved in dimethyl sulfoxide (DMSO) to prepare $200 \mathrm{mg} / \mathrm{mL}$ of $\mathrm{CsPbr}_{2.5} \mathrm{I}_{0.5}$ precursor solution. Polyacrylonitrile (PAN) was dissolved in DMSO to obtain a concentration of $10 \mathrm{mg} / \mathrm{mL}$. The precursor solution was mixed with PAN solution at a volume ratio of $1.5: 1$ and stirred overnight.

Pre-patterned indium tin oxide (ITO) glass substrates were sequentially washed with cotton balls dipped in acetone, ethanol, and deionized water, and ultrasonically cleaned in acetone and ethanol for $15 \mathrm{~min}$, respectively. The cleaned ITO glass substrate was transferred to a plasma cleaner for $30 \mathrm{~min}$. PEDOT:PSS and isopropanol solutions were mixed in a 20:1 volume ratio, stirred, treated by ultrasound for $30 \mathrm{~min}$, and then filtered. The solution was spin-coated onto an ITO substrate at $4000 \mathrm{rpm} / \mathrm{s}$ for $30 \mathrm{~s}$. Then, the substrate was annealed in air at $150{ }^{\circ} \mathrm{C}$ for $20 \mathrm{~min}$ and transferred into a glove box. For the fabrication of red PeLEDs, a perovskite precursor solution was spin-coated onto the HTL $(2000 \mathrm{rpm} / \mathrm{s}$ for $30 \mathrm{~s}$ ) by a one-step spin coating method. The substrate was annealed in a nitrogen atmosphere at $80^{\circ} \mathrm{C}$ for $10 \mathrm{~min}$ and then transferred into a vacuum thermal evaporation equipment connected to a glove box. Deposition of TPBi $(70 \mathrm{~nm}), \mathrm{Liq}(0.8 \mathrm{~nm})$, and Al $(140 \mathrm{~nm})$ were carried out under a high vacuum atmosphere $\left(\sim 5 \times 10^{-4} \mathrm{~Pa}\right)$. For the fabrication of white PeLEDs, PEDOT:PSS and $\mathrm{CsPbBr}_{2.5} \mathrm{I}_{0.5}$ precursor solutions were spin-coated onto ITO substrates, which were then annealed and transferred into a vacuum thermal evaporation equipment. A $10 \mathrm{~nm}$ thick NPB layer was deposited onto the substrate followed by another layer of $\mathrm{CsPbBr}_{3}$ synthesized by co-evaporation of $\mathrm{CsBr}$ and $\mathrm{PbBr}_{2}$. After that, TPBi $(70 \mathrm{~nm}), \mathrm{Liq}(0.8 \mathrm{~nm})$, and $\mathrm{Al}(140 \mathrm{~nm})$ were deposited successively.

The thickness and the deposition rate of each material layer were calibrated using an oscillating quartz thickness monitor. Photoluminescence (PL) spectra were measured using an RF-5301PC fluorescence spectrophotometer (Changchun, China). Electroluminescence (EL) spectra and CIE coordinates were measured using a PR655 spectra scan spectrometer (Changchun, China). Current-voltage-luminance characteristics were measured using an Agilent B290222A Precision Source/Measure Unit (Changchun, China) in the air at room temperature.

\section{Conclusions}

In this paper, we used a precursor solution containing an inorganic $\mathrm{CsPbr}_{2.5} \mathrm{I}_{0.5}$ perovskite and PAN polymer. A composite PAN:CsPbBr $2.5 \mathrm{I}_{0.5}$ film, prepared by a one-step method at low temperature, was used as the luminescent layer in red PeLEDs. The SEM and AFM results revealed a high coverage, compact, and uniform $\mathrm{PAN}: \mathrm{CsPbBr}_{2.5} \mathrm{I}_{0.5}$ composite film that effectively reduced current leakage. The introduction of the polymeric material PAN played an important role in controlling the morphology of the perovskite film, which means that the PAN:CsPbBr $2.5 \mathrm{I}_{0.5}$ mixed film can be used to make more efficient light-emitting devices. The device showed a maximum luminance value of $657 \mathrm{~cd} / \mathrm{m}^{2}$ at $8 \mathrm{~V}$. Moreover, the exciton distribution of the perovskite and organic small molecule materials, used as the luminescent layer in white electroluminescent devices, was analyzed. The device featured a turn-on voltage of $4 \mathrm{~V}$ and a maximum luminance value of $360 \mathrm{~cd} / \mathrm{m}^{2}$ at $7 \mathrm{~V}$. The color coordinate of the PeLED was $(0.31,0.36)$, which corresponds to an ideal white emission. Our innovative approach will encourage further developments in white perovskite LEDs.

Author Contributions: Proposed plan, data analysis and writing manuscript, S.C.; data collection and data analysis, C.C.; literature search, C.B.; manuscript modification, M.M.; manuscript modification, Y.L.; data analysis, P.C.; guiding experiment, data analysis and manuscript modification, Y.D.

Funding: This work was funded by the National Natural Science Foundation of China (Grants No. 61675088, 61275024, 61377026, and 61274002), the International Science \& Technology Cooperation Program of China (Grant No. 2014DFG12390), International Science \& Technology Cooperation Program of Jilin (Grant No. 20190701023GH), the National Key Research Program of China (Grant No. 2016YFB0401001), the Scientific and Technological Developing Scheme of Jilin Province (Grants No. 20140101204JC, 20130206020GX, 20140520071JH, and 20130102009JC), the Scientific and Technological Developing Scheme of Changchun (Grant No.13GH02), 
and the Opened Fund of the State Key Laboratory on Integrated Optoelectronics (Grants No. IOSKL2012KF01 and IOSKL2016KF08).

Conflicts of Interest: The authors declare no conflicts of interest.

\section{References}

1. Horng, R.H.; Wuu, D.S. An electroluminescent device using multi-barrier $\mathrm{Y}_{2} \mathrm{O}_{3}$ layers incorporated into ZnS:Mn phosphor layer. Mater. Chem. Phys. 1997, 51, 11-14. [CrossRef]

2. Duan, Y.; Wang, X. High-performance barrier using a dual-layer inorganic/organic hybrid thin-film encapsulation for organic light-emitting diodes. Org. Electron 2014, 15, 1936-1941. [CrossRef]

3. Yang, Y.X.; Duan, Y. High barrier properties of transparent thin-film encapsulations for top emission organic light-emitting diodes. Org. Electron 2014, 15, 1120-1125.

4. Lee, M.M.; Teuscher, J. Efficient hybrid solar cells based on meso-superstructured organometal halide perovskites. Science 2012, 338, 643-647. [CrossRef] [PubMed]

5. Kim, H.S.; Lee, C.R. Lead Iodide Perovskite Sensitized All-Solid-State Submicron Thin Film Mesoscopic Solar Cell with Efficiency Exceeding 9\%. Sci. Rep. 2012, 2, 591. [CrossRef] [PubMed]

6. You, J.B.; Meng, L. Improved air stability of perovskite solar cells via solution-processed metal oxide transport layers. Nat. Nanotechnol. 2015, 11, 75-81. [CrossRef] [PubMed]

7. Xing, G.C.; Mathews, N. Low-temperature solution-processed wavelength-tunable perovskites for lasing. Nat. Mater. 2014, 13, 476-480. [CrossRef]

8. Zhu, H.M.; Fu, Y.P. Lead halide perovskite nanowire lasers with low lasing thresholds and high quality factors. Nat. Mater. 2015, 14, 636-642. [CrossRef]

9. Yantara, N.; Bhaumik, S. Inorganic Halide Perovskites for Efficient Light-Emitting Diodes. J. Phys. Chem. Lett. 2015, 6, 4360-4364. [CrossRef]

10. Zhang, X.Y.; Lin, H. Enhancing the Brightness of Cesium Lead Halide Perovskite Nanocrystal Based Green Light-Emitting Devices through the Interface Engineering with Perfluorinated Ionomer. Nano Lett. 2016, 16, 1415. [CrossRef]

11. Song, J.Z.; Li, J.H. Quantum Dot Light-Emitting Diodes Based on Inorganic Perovskite Cesium Lead Halides $\left(\mathrm{CsPbX}_{3}\right)$. Adv. Mater. 2015, 27, 7162-7167. [CrossRef]

12. Protesescu, L.; Yakunin, S. Nanocrystals of Cesium Lead Halide Perovskites (CsPbX3, X $=\mathrm{Cl}, \mathrm{Br}$, and I): Novel Optoelectronic Materials Showing Bright Emission with Wide Color Gamut. Nano Lett. 2015, 15, 3692-3696. [CrossRef] [PubMed]

13. Chen, C.; Liu, Y.F. High efficiency warm white phosphorescent organic light emitting devices based on blue light emission from a bipolar mixed-host. Org. Electron 2017, 45, 273-278. [CrossRef]

14. Zhang, L.Q.; Yang, X.L. Ultra-bright and highly efficient inorganic based perovskite light-emitting diodes. Nat. Commun. 2017, 8, 15640. [CrossRef] [PubMed]

15. Tan, Z.K.; Moghaddam, R.S. Bright light-emitting diodes based on organometal halide perovskite. Nat. Nanotechnol. 2014, 9, 687-692. [CrossRef] [PubMed]

16. Chen, H.N.; Wei, Z.H. Solvent Engineering Boosts the Efficiency of Paintable Carbon-Based Perovskite Solar Cells to Beyond 14\%. Adv. Energy Mater. 2016, 6, 1502087. [CrossRef]

17. Wei, Z.H.; Zheng, X.L. A multifunctional C + epoxy/Ag-paint cathode enables efficient and stable operation of perovskite solar cells in watery environments. J. Mater. Chem. A 2015, 3, 16430-16434. [CrossRef]

18. Saliba, M.; Matsui, T. Cesium-containing triple cation perovskite solar cells: improved stability, reproducibility and high efficiency. Energy Environ. Sci. 2016, 9, 1989-1997. [CrossRef]

19. Sutton, R.J.; Eperon, G.E. Bandgap-Tunable Cesium Lead Halide Perovskites with High Thermal Stability for Efficient Solar Cells. Adv. Energy Mater. 2016, 6, 1502458. [CrossRef]

20. Mcmeekin, D.P.; Sadoughi, G. A mixed-cation lead mixed-halide perovskite absorber for tandem solar cells. Science 2016, 351, 151-155. [CrossRef]

21. Eperon, G.E.; Stranks, S.D. Formamidinium lead trihalide: A broadly tunable perovskite for efficient planar heterojunction solar cells. Energy Environ.Sci. 2014, 7, 982-988. [CrossRef]

22. Shan, Q.S.; Li, J.H. All-Inorganic Quantum-Dot Light-Emitting Diodes Based on Perovskite Emitters with Low Turn-on Voltage and High Humidity Stability. J. Mater. Chem. C 2017, 5, 4565-4570. [CrossRef] 
23. Cho, H.C.; Jeong, S.H. Overcoming the electroluminescence efficiency limitations of perovskite light-emitting diodes. Science 2015, 350, 1222-1225. [CrossRef] [PubMed]

24. Zhao, L.F.; Yeh, Y.W. In Situ Preparation of Metal Halide Perovskite Nanocrystal Thin Films for Improved Light-Emitting Devices. ACS Nano 2017, 11, 3957-3964. [CrossRef] [PubMed]

25. Li, J.Q.; Bade, S.G.R. Single-Layer Light-Emitting Diodes Using Organometal Halide Perovskite/Poly(ethylene oxide) Composite Thin Films. Adv. Mater. 2015, 27, 5196-5202. [CrossRef] [PubMed]

26. Ji, X.X.; Peng, X.F. On the performance of polymer: organometal halide perovskite composite light emitting devices: The effects of polymer additives. Org. Electron 2017, 52, 350-355. [CrossRef]

27. Wang, Z.B.; Luo, Z. Efficient and Stable Pure Green All-Inorganic Perovskite CsPbBr3 Light-Emitting Diodes with a Solution-Processed NiOx Interlayer. J. Phys. Chem. C 2017, 121, 28132-28138. [CrossRef]

28. Jin, F.M.; Zhao, B. Morphology control towards bright and stable inorganic halide perovskite light-emitting diodes. J. Mater. Chem. C 2018, 6, 1573-1578. [CrossRef]

29. Ling, Y.C.; Tian, Y. Optical and Electrical Properties of Polymer-Assisted All-Inorganic Perovskites for Light-Emitting Diodes. Adv. Mater. 2016, 28, 8983-8989. [CrossRef]

30. Madakbaş, S.; Çelik, Z. Preparation, characterization and electrical properties of polyacrylonitrile/huntite composites. Polym. Bull. 2014, 71, 1471-1481. [CrossRef]

Sample Availability: Samples of the compounds are available from the authors.

(C) 2019 by the authors. Licensee MDPI, Basel, Switzerland. This article is an open access article distributed under the terms and conditions of the Creative Commons Attribution (CC BY) license (http://creativecommons.org/licenses/by/4.0/). 